\title{
Medical Image of the Month: Superior Vena Cava Syndrome
}

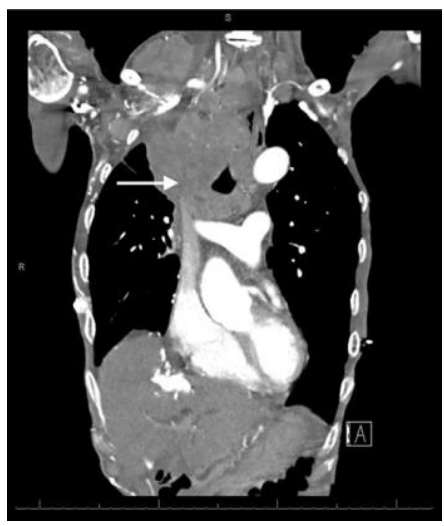

Figure 1. Coronal CT thorax with contrast showing a large apical mass with near complete atelectasis of the right upper lobe, mediastinal extension and effacement of the superior vena cava (arrow).

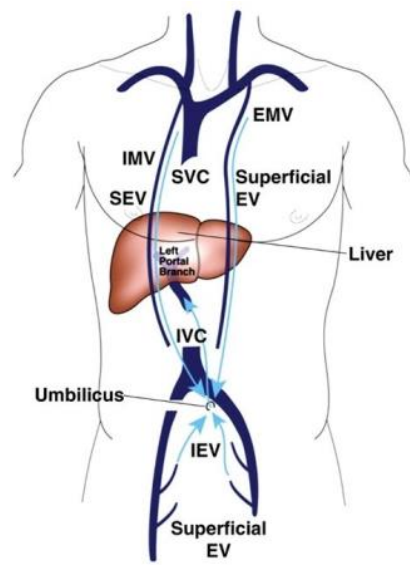

Figure 2. Caval-superficial-umbilical-portal pathway. $E M V=$ external mammary vein, $E V=$ epigastric vein, $I E V=$ inferior epigastric vein, $I M V=$ internal mammary vein, $S E V=$ superior epigastric vein (2).

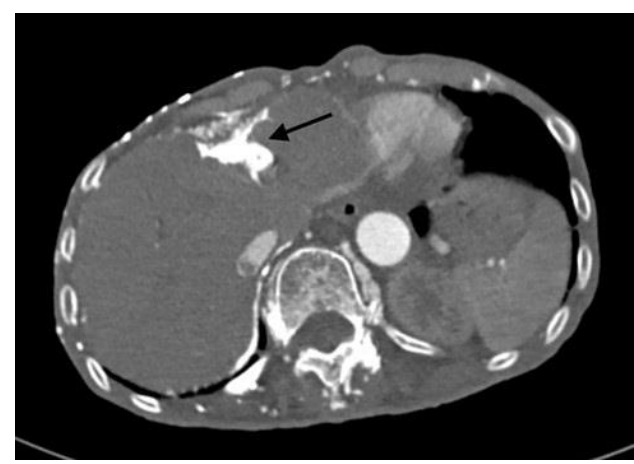

Figure 3. Axial CT thorax with contrast showing avid arterial enhancement of hepatic segment IV (arrow, hot quadrate sign), consistent with superior vena cava syndrome. 
Although superior vena cava syndrome (SVCS) may result from internal or external occlusion of the superior vena cava, $60-90 \%$ of cases are caused by external compression from malignant tumors, predominately lung cancer and lymphoma (1). Additional causes of SVCS via external occlusion include fibrosing mediastinitis, while internal occlusion may result from pacemaker lead or indwelling central venous catheter thrombosis (1). Symptoms of SVCS, such as facial and neck swelling, dyspnea and cough, typically develop over 2-4 weeks prior to diagnosis, during which collateral vessels develop (2). More severe symptoms of disease include laryngeal edema, cerebral edema, orthostatic syncope secondary to decreased venous return and altered mental status (3). In the presence of SVCS, cavoportal collaterals that may develop include caval-superficial-umbilical-portal pathways and caval-mammary-phrenic-hepatic capsule-portal pathways (3). Figure 2 demonstrates the anastomosis of inferior and superficial epigastric veins with internal and external mammary veins, allowing for recanalization of the paraumbilical vein and drainage into left portal vein. The presence of a caval-superficial-umbilical-portal pathway may be detected as a wedge-shaped area of increased enhancement in segment IV of the liver on CT or MRI, a radiographic finding known as the hot quadrate sign (Figure 3). Following diagnosis of SVCS in the setting of malignancy, goals of management may be palliative or curative and should take into account life expectancy. Endovascular stenting can provide near immediate symptomatic relief of SVCS, but requires the addition of chemotherapy, radiotherapy or combined-therapy if the goals of treatment are curative (1). Although the median life expectancy of a patient with SVCS due to underlying malignancy is often reported as 6 months, the prognosis is dependent on tumor type and the presence or absence of poor prognostic factors, including age $>50$ years old, history of tobacco use and treatment with corticosteroids (3).

Elliot Breshears MS IV, Lev Korovin MD, and Veronica Arteaga MD.

Department of Medical Imaging

The University of Arizona

Tucson, AZ, USA

\section{References}

1. Wan JF, Bezjak A. Superior vena cava syndrome. Hematol Oncol Clin North Am. 2010;24(3):501-13. [CrossRef] [PubMed]

2. Kapur S, Paik E, Rezaei A, Vu DN. Where there is blood, there is a way: unusual collateral vessels in superior and inferior vena cava obstruction. RadioGraphics. 2010;30(1):67-78. [CrossRef] [PubMed]

3. Manthey DE, Ellis LR. Superior vena cava syndrome (SVCS). In: Todd KH, Thomas CR Jr. Oncologic Emergency Medicine: Principles and Practice. Switzerland: Springer; 2016:211-222. Available at:

https://books.google.com/books?id= qQqDAAAQBAJ\&pg=PA211\&lpg=PA211\&dq= Manthey+DE,+Ellis+LR.\&source=bl\&ots=MWH6bcbHSf\&sig=L7UI5sfS1sSGBTF5cn K7MvKF9eA\&hl=en\&sa=X\&ved=2ahUKEwjGkoTC9LrdAhUEEHwKHbV2CF4Q6AE wAHoECAEQAQ\#v=onepage \&q=Manthey\%20DE\%2C\%20Ellis\%20LR.\&f=false (accessed 9/14/18). 